\title{
O COOPERATIVISMO COMO ESTRATÉGIA DE INSERÇÃO DOS ASSENTADOS DA REFORMA AGRÁRIA NOS MERCADOS DINÂMICOS: O CASO DA COPERTERRA
}

\author{
Data de submissão: $13 / 01 / 2014$ \\ Aceite: 20/05/2016 \\ Gabriel Murad Velloso Ferreira ${ }^{1}$ \\ Marta Von Ende ${ }^{2}$ \\ Gustavo Fontinelli Rossés ${ }^{3}$ \\ Pedro Selvino Neumann ${ }^{4}$
}

\section{RESUMO:}

O presente estudo se propõs a analisar o papel da organização social, por meio de uma cooperativa, na inserção dos assentados da reforma agrária do município de Tupanciretã - RS nos mercados dinâmicos da cadeia produtiva do leite. Para isto, realizou-se um estudo na Cooperativa Regional da Reforma Agrária Mãe Terra - COPERTERRA. Como principais resultados, verificou-se que a Coperterra está inserida nos mercados dinâmicos e tem demonstrado que a atividade leiteira se adéqua à realidade da pequena agricultura já que propicia uma renda mensal e que os riscos com a sazonalidade da produção podem ser amenizados com planejamento e organização da alimentação dos animais. Além disso, esta atividade possibilita que os agricultores tenham tempo para se dedicar à produção de outros alimentos, o que garante a diversificação da propriedade. Salienta-se que $10 \%$ do leite produzido é industrializado e comercializado nos mercados institucionais.

Palavras-chave: Reforma agrária. Leite. Mercados dinâmicos. Mercados institucionais. cooperativa.

\footnotetext{
1 Possui graduação em administração pela Universidade Federal de Lavras, mestrado em agronegócios pela Universidade Federal do Rio Grande do Sul e doutorado em extensão rural pela Universidade Federal de Santa Maria. É professor da Universidade Federal de Santa Maria. Santa Maria - RS. Brasil. E-mail: gabriel@ufsm.br

2 Possui graduação em administração e especialização em estatística e modelagem quantitativa pela Universidade Federal de Santa Maria, mestrado em administração pela Universidade Federal do Rio Grande do Sul e doutorado em administração pela Universidade Federal de Santa Maria. É professora da Universidade Federal de Santa Maria. Santa Maria - RS. Brasil. E-mail: marta@politecnico. ufsm.br

3 Possui graduação em administração, mestrado em engenharia de produção e doutorado em extensão rural pela Universidade Federal de Santa Maria. É professor da Universidade Federal de Santa Maria. Santa Maria - RS. Brasil. E-mail: gustavo@politecnico. ufsm.br

4 Possui graduação em agronomia e mestrado em extensão rural pela Universidade Federal de Santa Maria e doutorado em engenharia de produção pela Universidade Federal de Santa Catarina. É professor da Universidade Federal de Santa Maria. E-mail:neumannsp@ yahoo.com.br
} 


\section{INTRODUÇÃO}

O crescente aumento no consumo de alimentos tem motivado diversas ações no sentido de se garantir a segurança alimentar. Christoplos (2010) menciona que até 2050 a demanda por alimentos vai dobrar. No entanto, sabe-se que os pequenos produtores rurais estão sendo colocados para fora do mercado. Isto se dá em função das limitações impostas pelo mercado das principais commodities aos agricultores familiares, ou seja, um aperto (squeeze) sobre as condições de produção dos agricultores que tem levado a processos de descapitalização e inviabilidade econômica, o que Cochrane (1958 apud Röling, 2007) denominou de Agricultural Treadmill. E isto tem impactado no aumento do êxodo e da pobreza rural.

Vale ressaltar que a agricultura familiar é responsável por garantir boa parte da segurança alimentar do Brasil, pois tem se destacado como importante fornecedora de alimentos para o mercado interno. Esta participa com $87 \%$ da produção nacional de mandioca, $70 \%$ da produção de feijão, $59 \%$ do plantel de suínos, $58 \%$ do leite, $50 \%$ do plantel de aves, $46 \%$ do milho, $38 \%$ do café, $34 \%$ do arroz, $30 \%$ dos bovinos e $21 \%$ do trigo (IBGE, 2009). Além disso, a agricultura familiar responde por mais de $74 \%$ do pessoal ocupado no campo e por $10 \%$ do Produto Interno Bruto (PIB) brasileiro (MDA, 2011).

Dessa forma, verifica-se que, em um contexto de aumento pela demanda de alimentos, consciente de que os agricultores familiares têm grande relevância para a produção, mas que estão sendo colocados para fora do sistema, torna-se relevante adotar medidas que possibilitem que os agricultores familiares permaneçam no campo e produzam mais. Isto poderia auxiliar em duas problemáticas contemporâneas: segurança alimentar e pobreza rural.

Assim, a agricultura orientada para o mercado tem sido colocada como um avanço importante, pois, conforme aborda Christoplos (2010), existem oportunidades tanto nos mercados locais como nos distantes, seja por meio de maior agregação de valor ou aumento de volume nas commodities. $\mathrm{O}$ autor menciona que os pequenos (pobres) estão excluídos do mercado por dificuldade de manter padrão de qualidade, escala e pontualidade de entrega.

Ramirez et al. (2007) mencionam que o trabalho associativo é uma condição essencial para que famílias de territórios rurais pobres e marginalizados possam vincular-se exitosamente a mercados dinâmicos. A conotação de mercados dinâmicos não só se observa em espaços de venda extra-locais formais. Pelo contrário, observa-se que mercados locais com alto grau de informalidade também podem resultar em espaços de mercados dinâmicos para os territórios pobres e marginalizados (RAMIREZ et al., 2007).

No caso dos agricultores familiares, frente à falta de recursos e estrutura, o cooperativismo tem se mostrado eficiente na viabilização de unidades processadoras de alimentos. Em se tratando de cooperativas de assentados, Scopinho e Martins (2003) afirmam que a cooperação é uma ferramenta de luta política e social, na medida em que contribui para a sobrevivência econômica dos assentados, aumenta a produtividade do trabalho, racionaliza o uso dos recursos naturais e humanos e amplia a competitividade dos produtos no mercado.

Dessa forma, a existência de estruturas econômicas intermediárias, como as cooperativas, possibilita uma diminuição dos riscos e uma agregação de valor pra os produtores rurais que, isoladamente, em muitos casos, não teriam condições favoráveis de relacionamento com estes mercados concentrados.

Este é o caso da produção de leite. Dada a pulverização dos produtores e a grande concentração no setor industrial, as cooperativas de produtores de leite aparecem como uma alternativa para dar maior poder de barganha aos produtores bem como para posibilitar agregação de valor à produção. 
No caso do Rio Grande do Sul, entre os agricultores familiares, a pecuária de leite é uma das principais atividades desenvolvidas, estando presente em $48 \%$ dos estabelecimentos classificados como de economia familiar, além do fato de que estes respondem por $85 \%$ da produção de leite do estado (IBGE, 2009).

A importância desta atividade para as famílias de agricultores se manifesta no campo financeiro, visto ser uma fonte de renda mensal, que contribui sobremaneira para o equilíbrio do "caixa" da propriedade. No campo produtivo, a peculiaridade dos sistemas tecnológicos adotados pela ampla maioria dos produtores, permite sua perfeita adequação aos diferentes fatores de produção e a lógica de organização e gestão da unidade de produção familiar. No campo social, visto apresentar potencial para se estabelecer na quase totalidade das propriedades rurais, pode assegurar a criação de inúmeros postos de trabalho e gerar renda (FERRARI et al., 2004).

Vale ressaltar, que, de todas as cadeias produtivas do setor agropecuário, a que mais se transformou nos últimos anos foi a do leite. Após meio século de poucas mudanças, em grande parte explicadas pela forte intervenção do governo no mercado de lácteos, a cadeia produtiva do leite experimenta profundas transformações em todos os seus segmentos, da produção ao consumo (GOMES; PONCHIO, 2005).

A dinâmica do leite também está presente nos assentamentos rurais, o que faz com que os agricultores assentados busquem alternativas para comercialização e agregação de valor ao produto.

Essa realidade está presente no município de Tupanciretã - RS, que historicamente se caracterizou pela presença de grandes fazendas de produção pecuária, mas teve seu cenário alterado. Com a crise na produção animal, sua matriz produtiva migrou para produção de grãos, que tornou o município o maior produtor de soja do Rio Grande do Sul (IBGE, 2011a), com parte de suas terras destinadas à Reforma Agrária. Tal fato deu origem aos dezessete assentamentos existentes atualmente no local, que envolvem cerca de 700 famílias e incrementam a produção familiar e a dinâmica econômica e social do município.

Segundo Nunes e Balem (2003), os assentamentos de Reforma Agrária de Tupanciretã têm demonstrado uma clara orientação para o mercado e essencialmente para um único produto, a soja. A principal alternativa a esta orientação dominante tem sido a Bovinocultura de Leite, atividade largamente fomentada pelos movimentos sociais, o que resultou na criação de uma cooperativa voltada para o recolhimento e comercialização do leite: a Cooperativa Regional da Reforma Agrária Mãe Terra Ltda. (COPERTERRA).

O presente estudo se propõe a analisar o papel da COPERTERRA na inserção dos assentados da reforma agrária do município de Tupanciretã - RS nos mercados dinâmicos da cadeia produtiva do leite. Isto se torna relevante, pois se acredita que organizações de produtores, como o caso da Coperterra, podem auxiliar na produção de alimentos, na fixação do homem no campo e redução da pobreza rural no contexto da reforma agrária, conforme sinalizado por Scopinho (2007),

\section{AGRICULTURA ORIENTADA PARA O MERCADO}

Durante os últimos 20 anos, a expansão mundial de terras cultiváveis tem diminuído consideravelmente. Ao mesmo tempo, a população mundial deve chegar a quase 9 bilhões em 2050. Portanto, a produção global de alimentos terá que dobrar durante este período (SWANSON, RAJALAHTI, 2010).

Poole (2006) destaca que a globalização implica uma série de mudanças nos fatores econômicos e sociais, e estas mudanças geram oportunidades comerciais concretas para o meio 
rural de países em desenvolvimento, seja por meio das tendências (opostas) de diferenciação ou especialização. $\mathrm{O}$ autor ressalta que as barreiras colocadas pela globalização, para o acesso aos mercados, podem ser superadas por uma melhor organização da cadeia de suprimentos, no sentido de se obter escala e adquirir os conhecimentos técnicos necessários para se atuar nestes mercados. É muito provável que muitas commodities, assim como produtos locais e regionais, ofereçam oportunidades.

Segundo Ferris, Mundy e Best (2009), os mercados são dinâmicos, pois as preferências dos consumidores mudam constantemente, e estes passam a ser cada vez mais exigentes em termos de qualidade e no modo de produção dos produtos agroalimentares. Além disso, mudanças nas práticas de produção de uma parte do país ou mudanças nas políticas de outro país, que produz o mesmo produto, podem afetar a demanda e o preço do produto local.

Para enfrentar o desafio de manter a competitividade de seus produtos, os agricultores precisam buscar maneiras de tornarem-se mais eficientes na produção e comercialização, além de reduzir custos. Alternativamente, eles podem adicionar valor aos seus produtos, alterando a qualidade ou a forma como o produto é apresentado. Isto possibilita atender mais efetivamente às necessidades dos clientes e, consequentemente, conseguir um maior preço (FERRIS; MUNDY; BEST, 2009).

Uma possibilidade concreta para se obter ganhos no mercado trata-se de lançar mão de estratégias de associação. Ao esudar a gestão de cadeia de suprimentos no setor supermercadista, Livato e Benedicto (2010) salientam que a formação de redes é uma característica própria de mercados competitivos, em que ações de cooperação com o estabelecimento de parceiras para eliminar fases de intermediação dentro dos canais de distribuição podem funcionar como um mecanismo importante para pequenos e médios varejistas obterem vantagem competitiva.

Wilkinson (2003) considera que é necessário um amplo leque de estratégias de inserção da agricultura familiar no sistema agroalimentar, tanto no mercado commodities, que passa por formas de ação coletiva, como aproveitando oportunidades de mercado para produtos orgânicos ou com valorização regional (artesanais). Conforme Mior (2003), as estratégias presentes nas redes horizontais que envolvem adaptação de tecnologia às condições locais, mercado de proximidade e de nicho, diversificação da organização produtiva, dentre outras, são reveladoras da forma como os produtores constroem sua participação no mercado.

Segundo Desjardins (2010), as áreas rurais devem atrair renda que foi gerada no urbano. Para isto, a produção tem que ser orientada pelo mercado, exemplo disso são os produtos diferenciados como origem geográfica, orgânicos e fair trade, que são produtos voltados para o urbano, normalmente para classes mais altas.

Em pararelo a isto, Goodman (2004) destaca o movimento do quality turn, que consiste em uma mudança em relação ao padrão de consumo agroalimentar atualmente dominante. Embora o modelo produtivista de consumo e produção de massa ainda seja dominante, já existem indicações consistentes acerca de uma crescente demanda por alimentos mais saudáveis e de qualidade diferenciada, resultante de uma preocupação cada vez maior dos consumidores com os problemas de sanidade e de segurança alimentar. Assim, a qualidade assume um papel-chave no (re)estabelecimento da confiança entre consumidores e produtores de alimentos. Com isso, emerge uma valorização dos alimentos produzidos localmente, da produção orgânica e agroecológica, artesanal e das cadeias alimentares curtas, espaço de reconexão entre produtores e consumidores.

Nesse sentido, Ferrari (2011) menciona que se tem visto uma procura crescente por produtos locais, regionais ou diferenciados em detrimento dos padrões de consumo uniformes 
e globais. Esses produtos caseiros, típicos de um território, estão atrelados a um saber-fazer e técnicas de produção e de processamento localizados e a condições agroecológicas singulares. São precisamente estas características específicas que diferenciam o produto, ao constituir o verdadeiro capital humano e social. Essas características devem ser aproveitadas pela agricultura familiar já que abrem novas janelas de consumo que incorporam novos (ou reincorporam históricos) hábitos, identidades, experiências e valores culturais regionais.

Essa nova dinâmica econômica pode ser vista como uma forma de resistência para as forças desenraizadoras da globalização, permitindo que as regiões encontrem nichos para alimentos que apelam aos consumidores não sobre as bases de competitividade em preços, mas em termos de suas qualidades ecológicas, morais e estéticas. Há, portanto, um movimento consistente de mudança em relação ao padrão de consumo agroalimentar dominante na sociedade contemporânea, que vai do mundo industrial para o mundo doméstico, em que convenções de qualidade enraizadas na confiança, tradição e lugar apoiam produtos e formas de organização econômicas mais diferenciadas, localizadas e ecológicas (GOODMAN, 2004).

Por outro lado, Berdegué et al. (2008) destacam o papel fundamental das políticas públicas na promoção e apoio à transformação produtiva e no desenvolvimento institucional nas áreas rurais. Os autores mencionam que é preciso dar atenção prioritária para a inserção da agricultura familiar nos novos mercados domésticos para que seja possível uma revitalização da agricultura na América Latina. Uma estratégia para promover a pequena e média agricultura familiar dirigida aos novos mercados nacionais deveria, dentre outras coisas, desenvolver e modernizar os mercados nacionais para fazer frente com maior eficácia aos desafios e as novas demandas dos consumidores e das modernas cadeias de suprimentos, a exemplo de melhores padrões de qualidade e certificações (BERDEGUÉ et al., 2008).

Isto é reforçado pelo fato de que, conforme mencionam Ramirez et al. (2007), os territórios pobres são capazes de participar do mercado dinâmico, mas precisam de fortes apoios externos. Assim, fica clara a importância da extensão em trabalhar orientando os agricultores de forma a facilitar o acesso aos mercados (inclusive internacional) e melhorar os padrões de competitividade, o que também demanda investimentos públicos.

A participação de agricultores familiares nos mercados dinâmicos, sejam nacionais ou internacionais, geralmente se apresenta com uma característica em comum: diferenciação do produto e/ou do processo de produção. Isto implica inovações adotadas pelos agricultores para produzir produtos com características de qualidade que são valorizadas pelos consumidores, a exemplo de um atributo cultural, um valor social, relações sociais justas e éticas, respeito pela natureza e tradições indígenas. Trata-se de um processo complexo, mas que parece oferecer uma oportunidade valiosa para os agricultores pobres que não podem competir com base em seus ativos fixos e financeiros (BERDEGUÉ et al., 2008).

Binotto et al. (2009) enfatizam que a cooperativa se apresenta como um suporte aos produtores rurais, desempenhando um papel importante para a inovação, ao criar um ambiente com diferentes momentos de interação e de exposição a novas tecnologias, quer seja por meio de cursos, dias de campo, dentre outros meios.

Oliveira e Silva (2012) apontam que a construção de diferentes formatos associativos, como as cooperativas, tem sido uma das alternativas encontradas por trabalhadores e produtores autônomos e familiares, nas áreas urbanas e rurais, para viabilizar atividades de produção, de prestação de serviços, de comerciaização dentre outras, sendo que iniciativas dessa natureza constituem um novo conceito de inovação, a "inovação social".

Os pequenos produtores podem ter dificuldade em inserir-se nos mercados, devido à 
escala de produção reduzida, à dificuldade de acesso a serviços de assistência técnica e crédito, reforçando-se a importância de estruturas, como as cooperativas e associações, para auxiliar no processo de transferência de tecnologias e informações (KHERALLAH; KIRSTEN, 2002).

\section{ASPECTOS METODOLÓGICOS}

O método utilizado neste trabalho foi a pesquisa exploratória, que, conforme Gonçalves e Meirelles (2004), pode ser entendida como um processo investigativo que leva ao diagnóstico do verdadeiro problema, ou do problema relevante, que é a causa dos efeitos já presenciados. Esse tipo de pesquisa, segundo Gil (2006), tem por objetivo principal o aprimoramento de ideias ou a descoberta de intuições. Seu planejamento é flexível e considera as variáveis relativas aos fatos. Constitui no primeiro estágio da pesquisa científica, não tem o objetivo de resolver o problema de imediato, mas conhecê-lo e caracterizá-lo.

A pesquisa consistiu em um estudo de caso, tendo como objeto de análise a COPERTERRA. Para Yin (2010), o estudo de caso é um método de pesquisa que se presta a investigar o fenômeno dentro do seu contexto de vida real, no qual as fronteiras entre o fenômeno e o contexto não são claramente definidas e na situação em que múltiplas fontes de evidências são usadas.

Dessa forma, para se alcançar o objetivo de analisar o papel da COPERTERRA na inserção dos assentados da reforma agrária do município de Tupanciretã nos mercados dinâmicos da cadeia produtiva do leite, dividiu-se a coleta de dados em dois momentos.

O primeiro, caracteriza-se como a parte exploratória do estudo, no qual se realizou uma entrevista com o gerente da unidade de processamento da cooperativa. Vale ressaltar que a indústria de laticínios é de propriedade da Universidade Federal de Santa Maria, sendo que a Coperterra mantém convênio de utilização da planta fabril bem como da marca UNI.

A entrevista com o gerente teve como objetivo ter um primeiro contato com a realidade da cooperativa, buscando entender o histórico de sua constituição, as dificuldades, o contexto no qual está inserida, bem como informações de mercado, comercialização e perfil dos associados. Esta etapa fundamentou o segundo momento da pesquisa, que buscou aprofundar o entendimento nos aspectos históricos, mercadológicos, nos benefícios que a cooperativa oferece aos cooperados e também no papel da extensão/assistência técnica para a consolidação do leite como alternativa produtiva na região.

Para isto, realizou-se mais duas entrevistas em profundidade: uma com o presidente da cooperativa e outra com um agricultor que não faz parte da direção da cooperativa. Vale ressaltar que ambos são agricultores assentados e foram classificados como informantes qualificados. Dessa forma, para a realização do estudo foram realizadas três entrevistas em profundidade, sendo que cada uma teve duração média de duas horas. As entrevistas foram gravadas e posteriormente transcritas. Além das entrevistas, lançou-se mão da observação, já que as entrevistas foram realizadas em três ambientes que representam o todo do universo da cooperativa: uma propriedade rural, a sede da cooperativa e a indústria de beneficiamento.

As entrevistas foram norteadas por um roteiro semi-estruturado de questões elaborado previamente a partir das categorias a serem investigadas. As respostas foram analisadas à luz da técnica de análise de conteúdo que, de acordo com Bardin (1994), é uma técnica auxilia na sistematização dos objetivos e conteúdos indicando quantitativamente ou não a interferência de conhecimentos relativos a estas mensagens. Para a análise dos dados, procurou-se fazer a descrição e cruzamento das informações levantadas nas entrevistas. Assim, diversos trechos das 
entrevistas foram transcritos nos resultados, de forma a possibilitar o entendimento mais profundo das situações investigadas.

Cabe destacar que, por se tratar de uma pesquisa exploratória que se valeu de métodos eminentemente qualitativos, os resultados encontrados restringem-se ao caso estudado, não sendo generalizáveis.

\section{O município de Tupanciretã e o contexto de surgimento da Coperterra}

O município está localizado na região centro-oeste do estado do Rio Grande do Sul, e segundo IBGE (2011b), contava com população de 22.281 habitantes em 2010, dentre os quais 4.261 pessoas residiam em área rural, sendo que, conforme Michel (2009), 730 famílias viviam em assentamentos rurais. Partindo-se do pressuposto de que cada família possua um estabelecimento agropecuário, as famílias assentadas representam $54,6 \%$ de todos os estabelecimentos agropecuários de Tupanciretã, que, segundo o IBGE (2011a), alcançavam o total de $1.336 \mathrm{em}$ 2010. Vale ressaltar que existiam 247 unidades de assentados sem a titulação definitiva da terra em 2010 (IBGE, 2011b).

Tupanciretã destaca-se no Rio Grande do Sul por ter umas das maiores produções de soja do estado, bem como um grande número de assentamentos de Reforma Agrária. Em se tratando de soja, o município detém destaque na produção e produtividade, haja vista que em 2010 foi o maior produtor do Rio Grande do Sul e obteve rendimento médio de 43 sacas por hectare (IBGE, 2011b). Comparando-se os dados de 2006 e 2010, verifica-se uma evolução tanto na área plantada quanto no rendimento. A área plantada com soja saltou de 134.500 hectares em 2006 para 140 mil em 2010, já o rendimento saiu de 37,5 sacas/ha em 2006 para 43 sacas/ha em 2010 (IBGE, 2011b). Por outro lado, estão instalados dezessete projetos de assentamentos em Tupanciretã, sendo onze considerados sob coordenação política do Movimento dos Trabalhadores Rurais Sem Terra (MST).

Vale ressaltar que os dados sobre a produção leiteira no município estão evoluindo nos últimos anos. A partir das informações do IBGE (2011c), é possível verificar aumento no número de vacas de ordenha, na quantidade de leite e na produtividade. O rebanho passou de 4.200 cabeças em 2006 para 4.360 em 2010, um aumento de 3,8\% em 4 anos. No entanto, a produção teve um aumento mais intenso, evoluindo $58,9 \%$ neste mesmo período, saindo de 11.113 mil litros em 2006 para 17.658 mil litros em 2010. Isto pode ser explicado pelo ganho de produtividade de $53,4 \%$ no período.

A partir do que foi exposto, percebe-se que o município passou por uma mudança ou até mesmo uma adaptação com relação às suas atividades agropecuárias. Durante a entrevista com o presidente da Coperterra, o mesmo destacou como se deu o processo de mudança da matriz produtiva em Tupanciretã:

Houve uma mudança no município, antes era totalmente pecuário. Essa mudança entrou lá com a revolução verde, lá da década de 1980, que é quando estourou a revolução verde, mais com o plantio direto. Aí começou a transformação do campo para a soja. Então o pessoal começou a abrir campo e a produzir soja, porque Tupã é uma região muito boa para a soja, tem a terra arenosa. Na década de 1980 começou expandir a soja muito forte em Tupã (Entrevistado 2).

Por outro lado, na década de 1990 verificou-se uma intensificação da reforma agrária no município, conforme destaca o presidente da cooperativa: "de 1995 a dois mil e pouco chegaram uns cinco assentamentos. O negócio explodiu. Hoje em Tupã tem 17 assentamentos, são 700 famílias assentadas. A cidade melhorou muito depois dos assentamentos". Com isso, a necessi- 
dade de diversificação da matriz produtiva foi preponderante, já que a cultura da soja não viabilizaria o sustento das diversas famílias assentadas em lotes que variam de 12 a 20 hectares, como destaca o presidente: "ninguém sobrevive no lote só plantando soja. Tem que ter diversificação."

Dessa forma, o leite foi considerado uma alternativa viável em função da experiência dos assentados com a pecuária leiteira e pelo fato de o leite possibilitar um fluxo de dinheiro mensal nas propriedades.

Nós temos gente de vários lugares do Estado, vários municípios, de todos lugares. Pessoas que eram acostumadas com a produção do leite. Por isso, foi se incentivando a linha do leite, que é uma renda mensal que nós temos, que as pessoas conseguem pagar a luz, comprar as coisas para a subsistência. O pessoal começou a se organizar e a produzir leite. Tem a ver com a cultura das pessoas, porque a cultura de Tupã não é da produção do leite e sim do gado de corte. As famílias trouxeram essa cultura junto, vem do berço, lá do pai e da mãe (Entrevistado 2).

Um associado que foi entrevistado destacou que a entrada na produção do leite se deu também em função de que as terras que foram destinadas para a reforma agrária eram basicamente constituídas de pastagem: "era tudo campo, tinha gado de corte antes, daí mudar de gado de corte para gado de leite era mais tranqüilo" (Entrevistado 3). Além disso, o leite representa uma maior segurança com relação a intempéries climáticas e oscilações da produção:

Na seca por exemplo, as vacas diminuíram o leite, mas começou a chover as vacas começam a melhorar o leite de um dia para o outro. A soja não, produziu esse ano é só o ano que vem, e se dá uma seca, vai comer o quê? Passou o ciclo da soja, chega a dar um granizo, se foi. A vaca de leite pode até ficar mais magra, mais judiada, mas voltou a chover ela recupera de um dia para o outro. Além disso, tem a silagem e a ração que podem ser usadas (Entrevistado 2).

Diante deste contexto, os produtores iniciaram um processo de organização social para viabilizar a produção leiteira no município, já que os contratempos foram sentidos logo no início da atividade.

Com o início da produção começaram as dificuldades, as firmas de fora vinham recolher o leite, começaram a pagar pouco, porque só tinha uma firma e pagava o preço que queria. Diante disso, a gente começou a se organizar e decidimos a fundar uma cooperativa por uma necessidade nossa (Entrevistado 2).

Assim, é possível compreender o contexto no qual a experiência analisada está inserida.

\section{A constituição da Coperterra e o perfil dos associados}

Como o município de Tupanciretã é um polo da reforma agrária, mas sua matriz produtiva principal é a soja, o MST bem como as políticas institucionais do Ministério do Desenvolvimento Agrário (MDA) incentivaram a diversificação da produção nos lotes da reforma agrária e também na agricultura familiar de forma geral, sendo a produção de alimentos o grande objetivo. Dentro deste enfoque, a introdução (e ampliação) da atividade leiteira foi a estratégia principal.

Dessa forma, à medida que a atividade leiteira foi se consolidando, mas ainda em pequena escala, começaram a surgir as primeiras dificuldades. A principal delas era a comercialização. Segundo o entrevistado 1, "as empresas não queriam fazer rota de coleta em assentamentos" e também o "preço pago era muito baixo". Para enfrentar estes problemas, 34 famílias de Tupanciretã se uniram para constituir a Coperterra no ano de 2002.

As dificuldades continuaram, conforme o entrevistado 1 "a Coperterra contou no início com caminhão emprestado de outras cooperativas para fazer a coleta do leite". Por outro lado, 
"no primeiro mês de atividade o preço do leite dobrou". Assim, percebeu-se o potencial da cooperativa para viabilizar a produção leiteira na região. Como destacado na entrevista, "a Cooperterra estruturou a cadeia do leite em Tupanciretã". Esse comentário é reforçado pelo entrevistado 2:

No mês anterior que a cooperativa foi criada os agricultores estavam vendendo leite por $\mathrm{R} \$ 0,17 /$ litro, no mês seguinte com a criação da cooperativa o preço já foi para $\mathrm{R} \$ 0,28 /$ litro. $E$ logo a empresa já estava oferecendo $R \$ 0,45 /$ litro, já que muitos produtores estavam migrando para a cooperativa.

Atualmente, a cooperativa conta com cerca de 360 sócios (da reforma agrária e agricultura familiar), sendo que " $90 \%$ dos sócios são assentados, os demais são pequenos produtores da agricultura familiar" (Entrevistado 2). Nestas famílias, a renda principal é proveniente do leite, "75\% dos produtores vivem basicamente da renda do leite" (Entrevistado 2).

A Coperterra coleta cerca de 700 mil litros de leite por mês e, segundo o entrevistado 1 , "dentre as cooperativas do MST, esta é a cooperativa que mais recolhe leite no Rio Grande do Sul". O entrevistado 2 destaca a evolução no recebimento de leite da cooperativa: "a primeira rota nossa recolhemos 30 mil litros de leite/mês, depois 40,50 , hoje nós temos 700 mil, variando de 500 a 800 mil litros/mês".

Constata-se que a Coperterra desempenha um papel importante na ampliação da capacidade de sobrevivencia econômica por meio da obtenção de renda monetária maior para os assentados e na melhoria da infra-estrutura produtiva, aspectos que, segundo Scopinho (2007), fazem da cooperação uma alternativa importante para melhorar as condições de vida do pequeno produtor.

Ao longo da pesquisa procurou-se também identificar o perfil de associado mais comum na cooperativa, ou seja, o que mais se repete. Em se tratando de área, como já foi dito anteriormente, os módulos de terra dos assentamentos em Tupanciretã variam de 12 a 20 ha. Como $90 \%$ dos associados da Coperterra são provenientes da reforma agrária, pode-se dizer que $90 \%$ dos sócios estão nesse intervalo de área.

O plantel leiteiro médio é de 10 vacas por propriedades, sendo que destas, 5 a 6 permanecem em lactação. A produção média varia de 2000 a 2500 litros de leite por mês por produtor. Em se tratando de equipamentos, verificou-se que a maioria dos sócios dispõe de ordenhadeira mecânica bem como tanque de expansão a granel para armazenamento do leite. Vale ressaltar que a entrada no leite não resultou em abandono total da soja:

\begin{abstract}
Ainda existe a plantação de soja. A cultura da soja é bastante forte. São duas coisas: soja e leite. Tem uns que usam metade do lote em soja, outros estão só no leite. Só que o produtor de leite planta soja como rotação de cultura. A plantação da soja é um consórcio com a vaca de leite. Planta a soja no verão para poder botar uma pastagem de inverno. A soja em área pequena não dá dinheiro, é utilizada como rotação de cultura. O que planta milho, $80 \%$ do milho é feito silagem, ele se transforma em leite (Entrevistado 2).
\end{abstract}

Fontaneli et al. (2000) destacam que o sistema de integração lavoura-pecuária apresenta a vantagem econômica de diversificação da renda, resultante da produção vegetal e animal na mesma área, bem como o aumento da renda por área se comparado a sistemas não inegrados. No caso estudado, ficou explícito o entendimento por parte dos agricultores de que não seria possível a sobrevivência tendo como base produtiva somente a soja, ressaltando-se que a alternativa do leite foi viabilizada em função da constituição da cooperativa, como destaca o entrevistado 2: 
Hoje nós temos assentamento lá no fundão que se não fosse a Coperterra ter entrado, o pessoal já teria abandonado tudo. $90 \%$ saíram da soja, plantam só os cantinhos, porque antes não tinham alternativa, as pessoas plantavam milho, feijão, ali pra ti comer e o resto soja, porque não tinha outra opção.

A importância da cooperativa é reforçada pelo fato de que as empresas de forma geral "só entram nos assentamentos quando tiver estrada boa, os produtores estiverem organizados e produzindo de três mil litros ou mais por mês" (entrevistado 2).

Em relação à matriz produtiva dos associados, percebeu-se que estes são diversificados. A renda principal é proveniente do leite, mas produzem vários produtos para subsistencia, e o excedente também é comercializado pela cooperativa nos mercados institucionais como Merenda Escolar e Programa de Aquisição de Alimentos (PAA). Pereira e Lourenzani (2014) identificaram em seu estudo a importância do PAA para o escoamento do excedente da produção e o seu impacto no aumento da renda percebida pelo agricultor familiar.

Um agricultor, quando questionado sobre o que produzia na propriedade, mencionou que "nós só compramos fora arroz, sal, açúcar e café, produzimos batata, feijão, moranga, melancia, laranja, bergamota, pêssego, uva, tomate, hortaliças em geral, peixe, porco, galinha" (Entrevistado 3). O mesmo entrevistado também destaca que $90 \%$ da renda familiar vem do leite. O leite tem a função de custear todas as despesas da propriedade e da família, e que os demais alimentos produzidos compõem uma renda extra que viabiliza investimentos. Vale lembrar que normalmente os agricultores não contabilizam a produção para auto-consumo como renda.

É importante destacar que a Coperterra não é uma cooperativa só de leite. O entrevistado 2 ressalta que "a gente trabalha muito forte na diversificação da produção e a cooperativa viabiliza a comercialização."

Nós batemos muito na plantação da alimentação. Tanto é que nós temos uma feira aqui na cidade. Trabalhamos também com a merenda escolar, PNAE e PAA, tudo para ajudar a diversificar a produção. Nós não queremos que o associado fique só no leite. Nós queremos que tenha feijão, mandioca, hortaliça, frutas... (Entrevistado 2).

O presidente da cooperativa destacou que praticamente tudo que for produzido de alimento pelos agricultores a cooperativa consegue comercializar, inclusive que existe em um assentamento uma padaria que já fornece para o programa da merenda escolar.

Hoje a gente procura conscientizar o produtor que só de uma coisa não vive, se vai querer viver só do leite, colocar $100 \%$ em pastagem, ele vira uma monocultura, aí tem que comprar tudo na cidade. Se tiver tudo na propriedade, tu consome e vende o excedente.

É importante destacar que o preço recebido pelos alimentos fornecidos para o programa da merenda escolar é muito bem avaliado pelos produtores, já que o preço é definido com base em três preços do varejo.

\section{A Comercialização na Coperterra}

Em se tratando de comercialização do leite, a Coperterra possui duas linhas de atuação: o leite a granel e a industrialização, sendo que cerca de $10 \%$ são industrializados e $90 \%$ são direcionados in natura para outras indústrias. Para a comercialização do leite a granel, a cooperativa possui duas indústrias que são parceiras, ambas localizadas no Rio Grande do Sul, como destaca o entrevistado 2: "vendemos aproximadamente $50 \%$ para cada uma. Mas, a negociação é flutuante. Buscamos sempre o melhor preço para beneficiar o associado". É importante lembrar que, em função dos ganhos de escala possibilitados pela cooperativa, o preço recebido pelo leite a 
granel melhorou significativamente quando comparado com o preço médio que era recebido isoladamente por cada produtor.

No caso da produção industrializada (10\%), vale lembrar que a Coperterra possui um convênio com a Universidade Federal de Santa Maria (UFSM), por meio da Usina Escola de Laticínios da UFSM, onde são processados seus produtos e que também possibilita a comercialização dos produtos com a marca UNI, que já é consolidada na região há mais de 30 anos. Em função deste convênio, a cooperativa repassa $1,2 \%$ do seu faturamento para a UFSM. Os produtos industrializados são: leite pasteurizado (integral e desnatado), iogurte, bebida láctea, queijo (minas e tipo lanche), ricota, doce de leite e sorvete. Vale ressaltar que a primeira unidade industrial da Cooperterra está sendo construída no município de Tupanciretã e está em fase de conclusão.

A cooperativa possui dois canais de comercialização da produção que é industrializada: mercados institucionais e o varejo. Os mercados institucionais representam $90 \%$ das vendas e se constituem do fornecimento de leite pasteurizado, iogurte, bebida láctea, queijo, doce de leite e sorvete para os programas PAA (Programa de Aquisição de Alimentos) e PNAE (Programa Nacional de Alimentação Escolar). No entanto, o entrevistado 2 destacou que "o carro chefe da merenda escolar hoje é iogurte e bebida láctea. E conforme a demanda varia a indústria produz mais de um ou outro produto".

Segundo MDS (2011), o PAA propicia a aquisição de alimentos de agricultores familiares, com isenção de licitação, a preços compatíveis aos praticados nos mercados regionais. 0 programa também contribui para a formação de estoques estratégicos e para o abastecimento de mercado institucional de alimentos, que compreende as compras governamentais de gêneros alimentícios destinados a ações de alimentação empreendidas por entidades da rede socioassistencial; equipamentos públicos de alimentação e nutrição como restaurantes populares, cozinhas comunitárias e bancos de alimentos e para famílias em situação de vulnerabilidade social.

O Programa Nacional de Alimentação Escolar (PNAE) garante, por meio da transferência de recursos financeiros, a alimentação escolar dos alunos de toda a educação básica (educação infantil, ensino fundamental, ensino médio e educação de jovens e adultos) matriculados em escolas públicas e filantrópicas. O orçamento do programa para 2011 foi de $\mathrm{R} \$ 3,1$ bilhões, para beneficiar 45,6 milhões de estudantes. Com a Lei no 11.947, de 16/6/2009, 30\% desse valor (R\$ 930 milhões) devem ser investidos na compra direta de produtos da agricultura familiar (FNDE, 2011).

A Coperterra é uma cooperativa singular vinculada à Cooperativa Central dos Assentamentos do Rio Grande do Sul (Coceargs), que representa 250 assentamentos e 11 mil famílias no Rio Grande do Sul. E isto possibilita ganhos de escala e acesso a mercados mais distantes, como é o caso da região metropolitana, na qual a Coperterra está iniciando o fornecimento de alimentos via PNAE.

A outra via de comercialização dos produtos industrializados é o varejo, que escoa $10 \%$ da produção. É importante lembrar que a cooperativa tem registro na Coordenadoria de Inspeção de Produtos de Origem Animal - CISPOA ${ }^{1}$. Atualmente, a venda no varejo se resume em dois postos de vendas localizados na UFSM, sendo um no campus principal e outro no centro. Percebeu-se que a intenção é atuar cada vez mais no mercado institucional, pois segundo o entrevistado 2:

A merenda escolar é muito melhor que colocar no mercado. Por exemplo, na merenda escolar vendemos o leite a $R \$ 1,50$, se tu vai no mercado tem a concorrência com grandes empresas e o preço é $\mathrm{R} \$ 0,95$. Não tem como competir no varejo (Entrevistado 2).

1 A CISPOA é o órgão da Secretaria da Agricultura, Pecuária e Agronegócio do Rio Grande do Sul responsável pela inspeção de produtos de origem animal que são comercializados dentro do estado. 
Percebeu-se, inclusive, que a produção industrializada é viabilizada em função das compras governamentais:

Sem esses programas do governo nós não sobreviveríamos. Imagina se você paga $\mathrm{R} \$ 0,62$ no leite para o produtor, aí tem toda a industrialização e você vende por R \$0,95 para o mercado. Não tem condições. Nós somos limitados, é um caminhãozinho só, não temos quantidade (Entrevistado 2).

Quando questionado sobre uma possível vulnerabilidade em função da dependência quase que exclusiva das compras governamentais para a produção industrializada, o entrevistado 2 destacou que:

A nossa ideia é em cima do mercado institucional. Estamos ampliando a indústria para fornecer para esse mercado. A demanda existe. A agricultura familiar tem a DAP². É obrigado a colocar $30 \%$ da merenda escolar da agricultura familiar. Tem a lei. Nós temos essa válvula. Trabalhamos em cima dos 30\% (Entrevistado 2).

Em função dessa reserva de mercado, a cooperativa está construindo um laticínio próprio com capacidade de processamento de cerca de 100 mil litros de leite por mês. Esta indústria se somará à Usina Escola de Laticínios da UFSM que tem capacidade de processar até 200 mil litros de leite por mês. A intenção é aumentar a industrialização dos atuais $10 \%$ para $40 \%$ do leite coletado pela cooperativa: "se a gente conseguir vender $40 \%$ da nossa produção a $\mathrm{R} \$ 1,50$, vai melhorar demais para o produtor" (Entrevistado 2).

Apesar dos programas de compras governamentais de produtos da agricultura familiar abrirem uma importante janela de oportunidade para o desenvolvimento de empreendimentos no meio rural, Silva e Silva (2011) destacam que os resultados alcançados ainda possuem escala reduzida, tanto pelo seu orçamento, quanto pela dificuldade que existe por parte das organizações e dos municípios de acessarem suas modalidades. Dentre os desafíos existentes, os autores citam: infraestrutura deficiente para a logística da produção; necessidade de beneficiamento e agregação de valor aos produtos; e carência de assistência técnica especializada. Os autores complementam, ainda, que, embora os mercados institucionais sejam alternativas fundamentais para a comercialização de produtos da agricultura, é necessário que os empreendimentos busquem outras possibilidades de comercialização, para não ficarem reféns de políticas nas quais eles não têm governança quanto a sua continuidade, buscando desenvolver estratégias diferenciadas de acessos a mercados e articulação de redes e parcerias, com vistas a alcançar sua sustentabilidade e autonomia (SILVA; SILVA, 2011).

\section{Alguns Benefícios proporcionados pela Coperterra aos associados}

Em se tratando de benefícios que a cooperativa trouxe para os agricultores, pode-se destacar a viabilização da comercialização coletiva do leite, sendo que "hoje a cooperativa é a que melhor paga em Tupanciretã", ressalta o entrevistado 1. A cooperativa oferece também assistência técnica voltada para o manejo, alimentação do rebanho, processo produtivo e genética, de forma a contribuir em ganhos de produtividade, melhoria da qualidade e redução de custos. Para isto, dispõe-se de um veterinário e um técnico agrícola.

O veterinário da cooperativa dá assistência a todos os cooperados com um custo mínimo. Cobramos só os medicamentos e materiais utilizados. O técnico agrícola também faz a inseminação nos assentamentos mais próximos à cidade. E nos outros assentamentos, em todos tem o botijão de semem, e uma pessoa que tem curso e que faz a inseminação.

2 DAP: Declaração de Aptidão ao PRONAF (Programa Nacional de Fortalecimento da Agricultura Familiar). A DAP é utilizada como instrumento de identificação do agricultor familiar para acessar políticas públicas. 
É importante destacar que a cooperativa passou a realizar rotas de coleta em que as empresas tradicionais não percorriam, o que possibilitou que agricultores que estavam isolados participassem do mercado e agregassem renda na propriedade rural. Além disso, a cooperativa viabilizou a aquisição de resfriadores a granel por meio de financiamento e organização de grupos para utilização coletiva. Esta iniciativa, assim como a coleta do leite a granel em até 72 horas, são medidas capitaneadas pela cooperativa que possibilitaram melhoria na qualidade do produto e também a adequação dos produtores à Instrução Normativa 51 (IN 51) ${ }^{3}$.

A Coperterra dispõe também de uma loja agropecuária que fornece aos associados todos os insumos, ferramentas, equipamentos e medicamentos veterinários necessários para as atividades produtivas. $O$ cooperado conta ainda com a facilidade de as compras poderem ser descontadas do pagamento mensal do leite e ainda com parcelamentos. 0 entrevistado 2 destaca que "a cooperativa tem o diferencial de entregar a ração dentro do galpão do produtor, sendo que o não sócio não tem esse benefício".

A manutenção de resfriadores e instalação de ordenhadeiras também são realizadas por um funcionário da cooperativa sem custo de mão de obra para os cooperados. Existe também um trator com ensiladeira que faz a silagem a preço de custo para os cooperados: "hoje a hora de trator com ensiladeira é $\mathrm{R} \$ 150,00$, nós cobramos $\mathrm{R} \$ 60,00$ dos nossos cooperados" (Entrevistado 2).

A cooperativa também procura viabilizar a produção de alimentos, além do leite: "estamos fazendo que surjam outras opções de produção, se não gosta de produzir leite, tem o peixe, o mel, a horta, frutas. Nós não estamos só no leite, somos uma cooperativa de produção. Se o produtor quer plantar moranga, mandioca, produzir mel, nós vamos vender". Isto é importante para que os associados diversifiquem sua produção e garantam sua segurança alimentar e renda. "A Coperterra também organiza uma feira semanal em Tupanciretã, e tem a feira do peixe, que acontece na semana santa".

Um benefício que foi apontado por um agricultor (Entrevistado 3) se refere ao vale que a cooperativa emite e que é aceito como moeda corrente no comércio local. "Se eu preciso abastecer o carro, vou na cooperativa, pego o vale, vou lá e abasteço, se eu preciso ir no mercado, eu pego o vale, vou lá e compro. E só vai descontar quando vai acertar no leite".

Além desses benefícios diretos, a Coperterra tem uma atuação forte na comunidade, auxiliando na busca por melhores condições de vida e trabalho.

A gente faz muito o social. A cooperativa tem muito de brigar pela estrutura básica: por estrada, água, luz elétrica. Nesse período de estiagem colocamos o caminhão da cooperativa para puxar água para as pessoas. Temos peso nas solicitações na prefeitura. Participamos de uma reunião mensal na prefeitura para discutir o rural, e a Coperterra está inserida.

A qualidade de vida das pessoas hoje é muito boa. Quase todos têm luz elétrica, água encanada, a casa é humilde, mas é digna, sempre tem dinheiro no final do mês para pagar a luz, comprar um remédio, uma roupa para o filho. A maioria tem um carrinho pra andar, velho, mas, tem. Tem uma linha de crédito no banco, tem maquinário, tem um tratorzinho. A análise geral é que a cooperativa tem ajudado as pessoas a ter uma qualidade de vida boa e digna (Entrevistado 2).

A cooperativa também busca recursos, por meio de projetos, que melhoram sua estrutura e competitividade, bem como a eficiência produtiva dos associados. Alguns exemplos podem ser citados: um projeto financiado pelo INCRA para a compra de resfriadores; um projeto para plantar 1 ha de tifton em cada produtor, o que totaliza 360 ha. Há um projeto em andamento

3 A Instrução Normativa no 51 foi publicada pelo Ministério da Agricultura, Pecuária e Abastecimento (MAPA) com a preocupação da segurança alimentar da população consumidora e competitividade da indústria nacional. Os fundamentos da IN 51 são a sanidade, a higiene, a refrigeração e a nutrição animal (DÜRR, 2004). 
via Banco Nacional de Desenvolvimento Econômico e Social (BNDES) de 1,2 milhões a fundo perdido para custear um posto de resfriamento de leite, um caminhão truck de 500 mil litros só para fazer o transporte para as indústrias e um caminhão toco para a loja agropecuária. Vale ressaltar que a cooperativa já conta com uma frota de quatro caminhões próprios para a realização das rotas de coleta de leite.

Verificou-se que os benefícios oferecidos auxiliam a manter a fidelidade dos cooperados à Coperterra e que há consciência do papel da cooperativa.

Têm empresas que chegam aqui e oferecem cinco centavos a mais no litro de leite, mas a gente não vai porque sabe que eles só vem depois com o cheque na mão, e a Coperterra não, lá nós temos assistência técnica, tem a agropecuária, tem o vale, o trator. Quando nós fomos criar a cooperativa, a gente sabia que tinha que ter consciência. Podia até receber um pouco menos que de outras empresas, mas se a gente quisesse ter uma coisa nossa, pra ser menos explorado, pra ter alguém que defendesse nós, tinha que ter a cooperativa. Por isso que até hoje a maioria não saiu da cooperativa. Tem produtores que já saíram, mas depois voltaram, viram que não vale a pena (Entrevistado 3).

Esta fidelidade à cooperativa também foi destacada pelo presidente da Coperterra: "o associado de forma geral é fiel. Tem consciência de que é dono da cooperativa e que a cooperativa é parceira sempre e que oferece outros benefícios. As empresas sempre estão oferecendo mais pelo leite, mas a maioria não sai" (Entrevistado 2).

Em suma, ao estruturar a cadeia leiteira em Tupanciretã, verificou-se que a cooperativa viabilizou a diversificação produtiva em uma região caracterizada pelo monocultivo da soja, bem como se tornou um elemento central da dinâmica econômica do território. Isto contribui para a permanência dos agricultores assentados em seus lotes, já que a cooperativa possibilitou acesso aos mercados formais de alimentos, principalmente o do leite, bem como agregação de valor na produção rural. Vale lembrar que a cooperativa também possibilita a comercialização de atividades secundárias das propriedades, muitas delas de responsabilidade das mulheres, como é o caso de hortaliças, panificação, artesanato e de peixes. A agricultura familiar envolve a participação de todos os familiares na atividade produtiva, ainda que o trabalho feminino culturalmente muitas vezes não seja reconhecido na agricultura familiar por ser considerado um trabalho leve e de reprodução (ARRIAGADA, 1991). Nas unidades produtivas familiares que praticam a pluriatividade, as mulheres são atores centrais, combinando atividades tanto agrícolas como não agrícolas, diversificando e incrementando a fonte de renda familiar (SCOTT et al., 2012).

\section{CONSIDERAÇÕES FINAIS}

De forma geral, com este estudo, percebeu-se grande relevância da Coperterra no sentido de promover o acesso aos mercados agroalimentares, no caso o de lácteos, nos assentamentos da reforma agrária bem como na agricultura familiar do município de Tupanciretã. A cooperativa foi elemento estruturante da cadeia produtiva do leite no município, já que viabilizou a coleta, comercialização e industrialização do leite de famílias que estavam desenvolvendo suas atividades agropecuárias com base no monocultivo da soja. Desta forma, a cooperativa auxiliou no segmento da estratégia governamental (MDA) bem como dos movimentos sociais (MST) de inserir e ampliar a produção de alimentos na agricultura familiar e nos assentamentos da reforma agrária.

Os agricultores estavam excluídos do mercado, já que as empresas tinham restrição em fazer a coleta em assentamentos, bem como muitas rotas de leite eram consideradas inviáveis. 
Com isso, o esforço para a inserção e ampliação da atividade leiteira estava encontrando uma barreira, que só foi superada pela constituição da Coperterra. A partir da cooperativa, os agricultores passaram a acessar os mercados dinâmicos, neste caso o de lácteos, o que está de acordo com autores utilizados neste trabalho que discutem que existem oportunidades para os excluídos tanto no mercado de commodities como na agregação de valor (BERDEGUÉ et al., 2008; DESJARDINS, 2010; GOODMAN, 2004; POOLE, 2006; RAMIREZ et al., 2007; SWANSON, RAJALAHTI, 2010; dentre outros).

No caso da comercialização, a cooperativa possui dois canais de escoamento da produção leiteira: o do leite in natura e o de produtos industrializados. Na produção industrializada, conclui-se que não estão nos mercados dinâmicos, pois a comercialização se dá basicamente via mercados institucionais (PNAE e PAA). Por outro lado, 90\% da produção atual in natura é comercializada nos mercados dinâmicos, à medida que a produção é repassada para outras indústrias. $E$, nesse caso, o leite é vendido a preço de mercado. As melhorias de preço se dão em função do poder de negociação que a cooperativa passou a ter por negociar quantidades maiores.

Assim, a cooperativa está viabilizando a inserção nos mercados dinâmicos, pois os produtores estão garantindo sua sobrevivência com grande parte da comercialização do leite não processado sendo realizada no mercado convencional. No entanto, os mercados institucionais propiciam maiores ganhos, e a cooperativa está voltando sua atenção para ampliação desse mercado e, consequentemente, maior agregação de renda aos produtores associados.

A Coperterra está inserida nos mercados dinâmicos e tem demonstrado que a atividade leiteira se adéqua à realidade da pequena agricultura e dos agricultores familiares, já que propicia uma renda mensal, e que os riscos com a sazonalidade da produção podem ser amenizados com planejamento e organização da alimentação dos animais. Além disso, esta atividade possibilita que os agricultores tenham tempo para se dedicar a produção de outros alimentos, o que garante a diversificação da propriedade. Segundo um agricultor (entrevistado 3), "a gente tem aquele compromisso da ordenha cedo e à tardinha, no resto do dia a gente tem tempo pra produzir outras coisas com tranquilidade". Vale lembrar que a cooperativa também tem escoado toda a produção de alimentos dos associados, como é o caso do feijão, mandioca, tomate, hortaliças, frutas, peixes, pães, dentre outros. A maioria desta produção também é inserida nos mercados institucionais.

Percebeu-se que é possível que os agricultores familiares sobrevivam nos mercados dinâmicos tendo como atividade principal a produção de leite. No entanto, a organização social, neste caso em uma cooperativa, mostrou-se importante para viabilizar o acesso aos mercados dinâmicos e reduzir a vulnerabilidade dos produtores entrevistados que forneciam leite isoladamente para o setor industrial.

Em se tratando de industrialização, percebeu-se que a cooperativa trabalha com produtos similares aos das empresas convencionais de laticínios. Mesmo com a agregação de valor, não se verificou diferencial dos produtos industrializados com relação aos demais que estão no mercado. Com isso, constatou-se que a cooperativa não trabalha na perspectiva defendida por Goodman (2004), na qual convenções de qualidade enraizadas na confiança, tradição e lugar apoiam produtos e formas de organização econômicas mais diferenciadas, localizadas e ecológicas.

Por outro lado, é necessário ressaltar certa dificuldade da cooperativa em se manter competitiva no mercado de leite industrializado, livre da proteção do Estado. No entanto, percebeu-se claramente que a Coperterra está intensificando a estratégia de industrialização e que o foco recai quase que exclusivamente no mercado institucional. 


\section{REFERÊNCIAS}

ARRIAGADA, Irma. Mujeres rurales de América Latina e el Caribe: resultados de programas y proyectos. In: Una nueva lectura: genero en el desarrollo. Entre Mujeres. Flora Tristan Ediciones. Perú, 1991.

BARDIN, L. Análise de conteúdo. Lisboa: Edições 79, 1994.

BINOTTO, E.; SIQUEIRA, E. S.; NAKAYAMA, M. K. Criação de conhecimento no agronegócio: estudos de casos. Revista de Administração da UFSM, v.2, n.3, p.367-384, set./dez. 2009.

BERDEGUÉ, J.A.; SCHEJTMAN, A.; CHIRIBOGA, M.; MODREGO, F.; CHARNAY, R.; ORTEGA, J. Agricultura para El desarrollo: hacia uma agenda regional para América Latina. Santiago. RIMISP. 2008.

CHRISTOPLOS, I. Mobilizing the potential of rural and agricultural extension. FAO. Roma. 2010.

DESJARDINS, D.R. The LAS approach: a scheme for sustainable local development of southern countries rural áreas? In: $116^{\text {th }}$ EAAE Seminar "Spatial dynamics in agri-food systems: implications for sustainability and consumer welfare". Italy. 2010.

DÜRR, J. W. Programa nacional de melhoria da qualidade do leite: uma oportunidade única. In: DÜRR, J. W.; CARVALHO, M. P.; SANTOS, M. V. (Eds.). O compromisso com a qualidade do leite no Brasil. Passo Fundo: Editora Universidade de Passo Fundo. 2004.

FERRARI, D.L. Cadeias agroalimentares curtas: a construção social de mercados de qualidade pelos agricultores familiares em Santa Catarina. Tese (Doutorado em Desenvolvimento Rural) Universidade Federal do Rio Grande do Sul, Porto Alegre. 2011.

FERRARI, D.L.; MELLO, M.A. de; TESTA, V.M.; SILVESTRO, M. L. Agricultura familiar, produção de leite e desenvolvimento territorial: os desafios para a inserção econômica. In: XLII Congresso Brasileiro de Economia e Sociologia Rural. Cuiabá. 2004.

FERRIS, S.; MUNDY, P.; BEST, R. Getting to market: from agriculture to agroenterprise. New York. Catholic Relief Services/USAID. 2009.

FNDE. Programas de alimentação escolar. 2011. Disponível em: <http://www.fnde.gov.br/index. php/programas-alimentacao-escolar>. Acesso em 07 out. 2011

FONTANELI, R.S. et al. Análise econômica de sistemas de produção de grãos com pastagens anuais de inverno, em sistema de plantio direto. Pesquisa Agropecuária Brasileira, Brasília, v.35, n.11, p.2129-2137, 2000.

GIL, A. C. Como elaborar projetos de pesquisa: 4.ed. São Paulo: Atlas. 2006.

GOMES, A.L.; PONCHIO, L.A. A Função custo no setor do leite: Uma abordagem para a região centro-sul do Brasil. CEPEA. 2005.

GONÇALVES, C. A; MEIRELLES, A. M. Projetos e relatórios de pesquisa em administração. São Paulo: Atlas. 2004.

GOODMAN, D. Rural Europe redux? Reflections on alternative agro-food networks and paradigm 
change. Sociologia Ruralis, 44(1). 2004.

IBGE. Censo Agropecuário 2006: Agricultura Familiar - Primeiros Resultados. Brasil, Grandes Regiões e Unidades da Federação. Rio de Janeiro. 2009.

IBGE. Censo Agropecuário 2006: IBGE cidades. Disponível e $\mathrm{m}:<$ http://www.ibge.gov.br/cidadesat/comparamun/compara. php?codmun $=432220 \&$ coduf $=43 \&$ tema $=$ censoagro $2006 \& \operatorname{codv}=v 168 \&$ lang $=>$. Acesso em 24 out. 2011a.

IBGE. Resultados Preliminares do Universo do Censo Demográfico 2010. Rio de Janeiro. Disponível em: <http://www.ibge.gov.br/cidadesat/topwindow.htm?1>. Acesso em 01 nov. 2011b.

IBGE. Produção da Pecuária Municipal 2010. Rio de Janeiro. Disponível em: <http://www.ibge.gov. br/cidadesat/topwindow.htm?1>. Acesso em 01 nov. 2011c.

KHERALLAH, M.; KIRSTEN, J. F. The New Institutional Economics: applications for agricultural policy research in developing countries. Agrekon, South Africa, v. 41, n. 2, p. 110-133, Jun. 2002

LIVATO, M.; BENEDICTO, G. C. Uma proposta de reestruturação dos canais de distribuição como vantagem competitiva no varejo de alimentos. Revista de Administração da UFSM, v.3, n.3, p.361374, set./dez. 2010.

MDA. Plano safra da agricultura familiar 2011/2012. Brasília. 2011.

MDS. Programa de Aquisição de Alimentos. Disponível em: <http://www.mds.gov.br/ segurancaalimentar/alimentoseabastecimento/paa>. Acesso em 07 out 2011. 2011.

MICHEL, T. Acompanhamento da elaboração dos planos de recuperação dos assentamentos dos projetos de assentamentos do município de Tupanciretã, RS. Monografia (Graduação em Medicina Veterinária)- Universidade Federal do Rio Grande do Sul, Porto Alegre, 2009.

MIOR, L. C. Agricultores familiares, agroindústrias e território: a dinâmica das redes de desenvolvimento rural no Oeste Catarinense. Tese (Doutorado Interdisciplinar em Ciências Humanas - Sociedade e Meio Ambiente)- Universidade Federal de Santa Catarina. Florianópolis, 2003.

NUNES, P.B.; BALEM, T. Reforma Agrária e Agroecologia: um modelo em construção. Congresso Brasileiro de Agroecologia. Porto Alegre. 2003.

OLIVEIRA, N. D. A.; SILVA, T. N. Inovação social e tecnologias sociais sustentáveis em relacionamentos intercooperativos: um estudo exploratório no Creditag - RO. Revista de Administração da UFSM, v. 5, n.2, p.277-295, mai./ago. 2012.

PEREIRA, M. E. B. G.; LOURENZANI, A. E. B. S. Desafios e perspectivas do programa de aquisição de alimentos no municipio de Tupã - SP. Ciência e Natura, v. 36, n.2, p.230-240, mai./ago. 2014.

POOLE, N. La población rural pobre ante los retos, dificultades y posibilidades que plantea la innovación. Roma. FIDA. 2006.

RAMIREZ, E.; PINO, R.; ESCOBAR, G.; QUIROZ, O.; RUIZ, R.; SARMIENTO, L.D.; ESCHEVERRÍA, J.A. Vinculación a mercados dinâmicos de territórios rurales pobres y marginados. Grupo Chorlaví. 
2007.

RÖLING, N. La comunicación para El desarrollo em La investigación, La extensión y La educación. In: FAO (Org.). Comunicación y desarrollo sustenible. Roma. 2007.

SCOPINHO, R. A.; MARTINS, A. F. G. Desenvolvimento organizacional e interpessoal em cooperativas de produção agropecuária: reflexão sobre o método. Psicologia \& Sociedade, n. 15 (2), p. 124-143, jul./dez., 2003.

SCOPINHO, R. A. Sobre cooperação e cooperativas em assentamentos rurais. Psicologia \& Sociedade, n. 19 (1), Edição Especial, p. 84-94, 2007.

SCOTT, P.; CORDEIRO, R.; MENEZES, M. Um olhar de gênero e de geração nos universos rurais. Estudos Feministas, v. 20, n.2, p.583-592, mai./ago. 2012.

SILVA, M. G.; SILVA, S. P. Para além do acesso: uma análise da relação entre mercados institucionais e empreendimentos de economia solidária no meio rural. IPEA Mercado de trabalho, v. 49, nov. 2011.

SWANSON, B. E.; RAJALAHTI, R. Strengthening agricultural extension and advisory systems: procedures for assessing, transforming, and evaluating extension systems. Washington. World Bank. 2010.

WILKINSON, J. A agricultura familiar ante o novo padrão de competitividade do sistema agroalimentar na América Latina. Estudos- Sociedade e Agricultura. Rio de Janeiro, n. 21, p. 6287. 2003.

YIN, R. K. Estudo de caso: planejamento e métodos. Porto Alegre: Bookman, 2010. 